\title{
Suture Edge Tension Control Technologies for Scar Improvement
}

Luc Téot, Sergiu Fluieraru, and Christian Herlin

\section{Contents}

\subsection{Background -498}

\section{$\mathbf{5 7 . 2}$ Introduction/Objectives $\mathbf{- 4 9 8}$}

57.3 Description of the State of the Art, Historical Evolution, and Recent Data - 498

57.3.1 Silicone Devices - 498

57.3.2 Reinforced Suture Materials - 498

57.3.3 Adjustable Tensors - 499

57.3.4 Closed Incision Negative Pressure Therapy - 500

$\mathbf{5 7 . 4}$ Conclusion $\mathbf{- 5 0 1}$

References - 501 


\subsection{Background}

Suture management after closure has been considered as highly important in the prevention of enlargement and infection. The rupture of skin integrity, the surgical dissection, and subsequent trauma of the underlying structures may cause local inflammation, edema, dehiscence, and infection. In this context, new technologies were developed and recently validated. The aim of this chapter is to highlight the role of mechanotherapy in prevention of postoperative complications on the suture line. This chapter is designed for surgeons facing surgical procedures at risk of infection or dehiscence or willing to reduce the scar enlargement after surgery on a visible area.

\subsection{Introduction/Objectives}

The tension exerted on the edges after cutaneous excision surgery has been demonstrated as a source of inflammation and potential complications, like local infection, scar enlargement when skin edges are, even minimally, separated [1, 2]. Keloid generation as well as hypertrophic scarring has been related to mechanical forces in experimental and clinical studies confirming the importance of mechanical control in the prevention of pathological scars especially in Asia [3]. Several techniques have recently been described on the basis of the principle of immobilizing the suture edges after surgery [1].

Globally a better understanding of scar mechanics has been under way for several years [2]. This has made it possible to multiply the compression strategies offered by compression garments or Orlen ${ }^{\circledR}$ (Professional Plastics, Fullerton, CA) plates, particularly in burn scars [4]. Translational research has been stimulated and the optimization of mechanical devices exploiting mechanical forces has been developed, especially in the field of wound healing [5].

A recent study [6] on cadavers measured the forces of tension exerted on the edges of sutured skin and the underlying aponeurosis. These measurements can be considered as a basis for measuring the reapproximation forces of the edges in human clinical practice. A three-dimensional simulation model allowed for reproducing the in vivo tension experienced by the skin, the phenotype of fibroblasts from keloid scars, their matrix synthesis capacity under tension, and in vivo skin tension measured on volunteers. It has been demonstrated that the induction of tension modifies the expression of the genes linked to the mechanical tension of the fibroblasts. This mechanical regulation makes it possible to understand that an increased synthesis of collagen occurs in the scar via the fibroblasts when tension is exerted strongly on the edges. The therapeutic interest of this hypothesis serves as a basis for the development of medical devices opposing edge tension.

\subsection{Description of the State of the Art, Historical Evolution, and Recent Data}

Applying materials over the suture after surgery is a longtime practice.

In the 2000, the first international consensus [7] on scar management emphasized the positive role of silicone but did not pay too much attention to the adhesive tapes, the first cheap device supposed to limit tension on the suture edges.

\subsubsection{Silicone Devices}

Silicone gels and tapes have been used since 1986 in prevention and treatment of hypertrophic scars and keloids. Although there have been multiple randomized controlled trials evaluating the efficacy of silicone gels [8], the overall quality of evidence is limited [9].

Silicone gels remain the most reported technique in the successive guidelines published since 2002. Silicone is not per se exerting any tension on the skin edges but may contribute to skin moisture.

\subsubsection{Reinforced Suture Materials}

During recent years a resorbable barb suture was developed, aiming at distribution of tension along the wound, providing a stronger wound edge approximation. The device was made of slowly resorbable material acting as a barber suture, due to obliquely distributed regular cuttings in the core of the device, preventing longitudinal movements on the suture line. The system was proposed as a drastic change in the suturing methods with a single-layer closure facilitated versus a 2-layer closure. Scar revision including large resection, prevention of shearing forces consequence on flap edges, and situations where the suture line may be exposed to mild to moderate tension were indications for the device [10].

Adhesive sutures. Used since decades long term, these paper tapes are placed over the skin edges to maintain a minimal pressure. Forces exerted on the suture are low, the adherence of the paper embedded with glue being solubilized or detached either by the exudation liquids or by the movements. Reiffel could demonstrate some superiority when adhesive sutures were placed longitudinally on the edges instead of transversally as a scale [11].

Self-adherent smart silicone has been proposed as a solution offering a permanent pressure exerted on the skin edges by a smart technology using adherent silicone covering the suture, isolating the suture from any external contamination. A mechanomodulating polymer device was utilized to manipulate the mechanical environment of closed cutaneous wounds in red Duroc swine, by 
local needs and the wishes of the surgeons. The system can be positioned immediately after surgery and maintained in situ during subsequent weeks (• Fig. 57.3).

The tension adjustment makes it possible to avoid even minimal edge spacing, which is a source of bacterial penetration and secondary infection. Moreover, the separation movements exerted longitudinally by the natural movements of the body are blocked, and this limitation serves as a transverse but also longitudinal immobilization. This is an essential factor in wound healing, limiting local inflammatory phenomena. Once the tension is stabilized, the loops are cut at their base.

In the author series of 21 clinical cases of skin excision [14], Zipline ${ }^{\circledR}$ was used after tumor resections, scar revision, or flaps. The tension exerted on the edges was variable and Zipline ${ }^{\circledR}$ was able to maintain the suture line outside of the transverse and longitudinal mechanical stresses. The results obtained in this series showed a maintenance of the linear scar measuring less than $0.5 \mathrm{~cm}$ permanently after 2 months of application. No local inflammation or secondary enlargement was observed after 2 months.

The anatomical sites were multiple and dependent on the necessities of the surgery. Most areas were located on the shoulders and back, regions known for their dermal fragility and problematic scarring. Maintaining a linear scar on these regions is difficult, especially in young women, after nevus resection. The skin's natural mobility, its thickness, and the forces exerted produce areas of known risk.

All patients underwent cutaneous resection during surgery, with skin loss between $4 \mathrm{~cm} \times 3 \mathrm{~cm}$ and $8 \mathrm{~cm}$ $\times 14 \mathrm{~cm}$. The postoperative scars were either straight or slightly curvilinear, and the maximum effect seemed to be obtained when the system was applied to rectilinear scars (• Figs. 57.1, 57.2, 57.3, and 57.4). - Table 57.1 summarizes the population studied and the amounts of skin resected during surgery. The system was applied for an average of 42 days, with three changes on average.

The evaluation of the scar was performed by three independent evaluators. The average follow-up was $6 \pm 3$

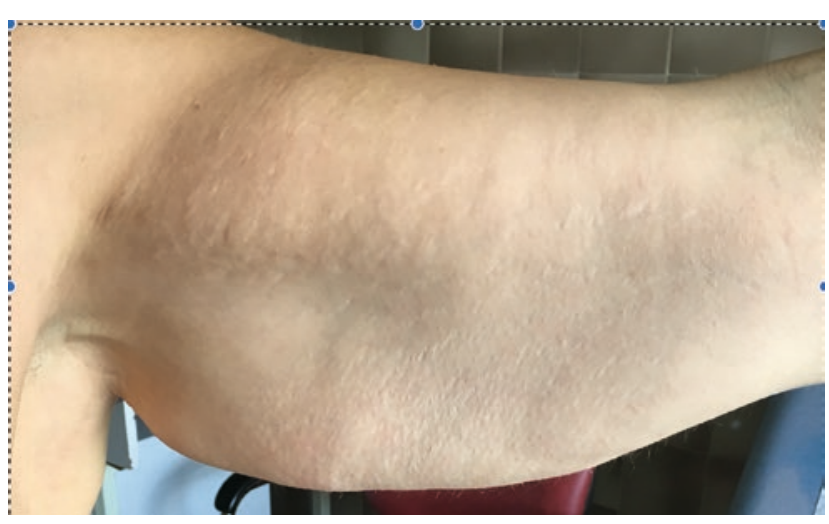

Fig. 57.1 Right arm presenting excessive fat volume (postbariatric surgery) 


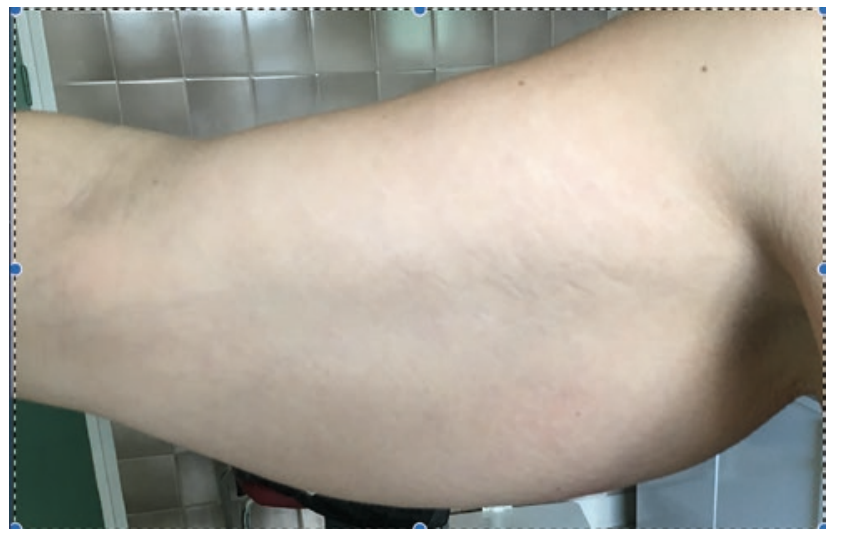

- Fig. 57.2 Left arm presenting excessive fat volume

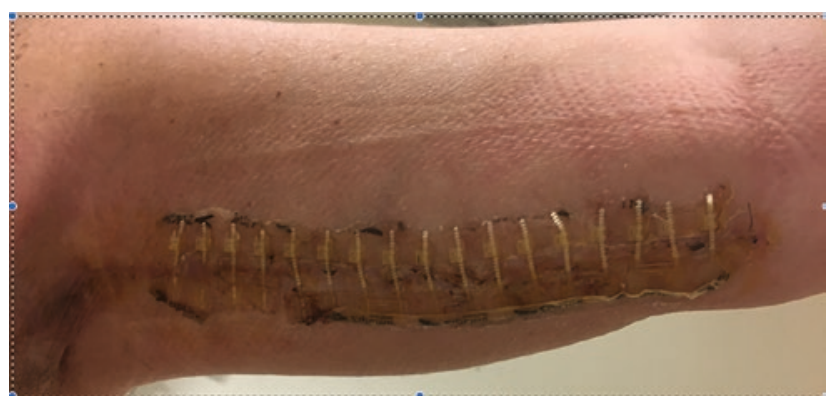

- Fig.57.3 Right arm 2 months after fat reduction and suture edge control

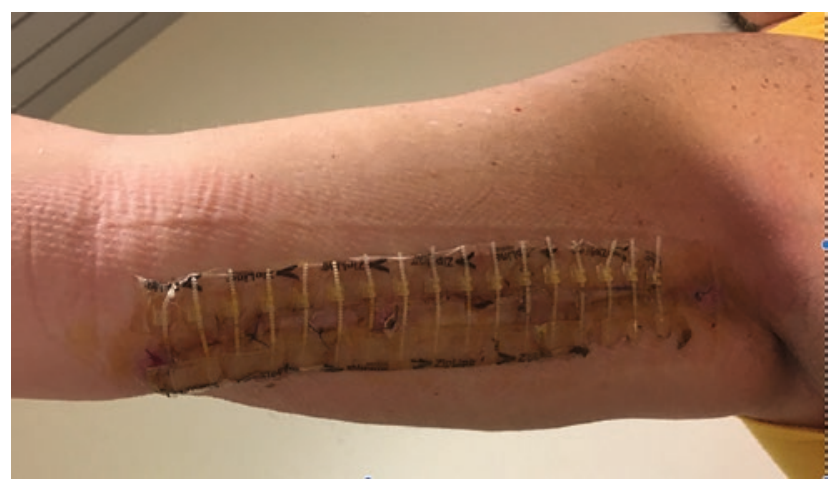

- Fig. 57.4 Left arm 2 months after fat reduction and suture edge control months. The results were considered positive when the scar remained linear without secondary enlargement after 6 months.

Zipline ${ }^{\circledR}$ could be proposed as a skin closure system and as an alternative to epidermal suturing. However, it has not yet been used as a tool to maintain mechanical tension after suturing during cutaneous resection.

The distraction forces exerted on a suture line are caused by the patient's movements. The Zipline ${ }^{\circledR}$ system creates an immobilization of the micromovementgenerating forces on the suture edges, which are sources of disunion and scar enlargement. Thanks to the polyurethane core and its staggered arrangement on the adhesive strips, any type of movement can be prevented because it opposes both transverse and longitudinal forces. This compression can be considered dynamic, and it prevents the widening of the suture, regardless of the movement to which it is subjected.

Several clinical trials reporting the effects of Zipline ${ }^{\circledR}$ have recently been published [15-19]. These trials report the product's good capacity to be used in the final closure of wounds. In our series, it appears that maintenance in place for several weeks on the skin serves to limit postoperative mechanical tension and to minimize scars, even in areas in tension and after keloid excision.

Zipline ${ }^{\circledR}$ has been proposed in multiple disciplines like orthopedic surgery in mobile areas like knee or shoulders and in plastic surgery after cutaneous excision for scar revision, cutaneous tumor excision, and loss of cutaneous substances due to chronic wounds such as pressure sores.

\subsubsection{Closed Incision Negative Pressure Therapy}

Several recent studies demonstrate the value of isolating the wound from any source of external contamination and of keeping it under slight tension.

In recent years, the indication for negative pressure wound therapy (NPWT) has been extended to include treatment of closed surgical incisions (incisional NPWT, iNPWT). Some of the first studies were case series and observational studies [20] using one of the exist-

- Table 57.1 Closed incision NPWT clinical indications

\begin{tabular}{|l|l|l|l|l|l|}
\hline CiNPWT clinical indications & Thoracic surgery & Caesarian section & Orthopedic surgery & Postskin grafting & Pilonidal sinus \\
\hline PICO ${ }^{8}$ & $\mathrm{x}$ & $\mathrm{x}$ & $\mathrm{x}$ & $\mathrm{x}$ & $\mathrm{x}$ \\
\hline Avelle ${ }^{\circledR}$ & & $\mathrm{x}$ & $\mathrm{x}$ & $\mathrm{x}$ & $\mathrm{x}$ \\
\hline Prevena ${ }^{\circledR}$ & $\mathrm{x}$ & $\mathrm{x}$ & $\mathrm{x}$ & $\mathrm{x}$ & $\mathrm{x}$ \\
\hline Nanova & & & \\
\end{tabular}


ing NPWT devices (VAC®; KCI, San Antonio, Texas, USA) [21, 22] designed for open wounds. Two simplified NPWT devices became commercially available in 2010 (Prevena $^{\mathrm{TM}}$; KCI) and 2011 (PICO ${ }^{\mathrm{TM}}$; Smith \& Nephew, Hull, UK). These NPWT devices consist of a singleuse battery-powered negative-pressure therapy device, an easy-to-place dressing, and either a very small and easily portable canister, or no canister at all. In the latter case, the liquid is removed by evaporation through a semipermeable dressing. The mechanisms of action of this closed incision management have been supported by biomechanical studies:

Biomechanical testing could experimentally demonstrate that a pressure of $80 \mathrm{mmHg}$ applied over a suture was enough to prevent $55 \%$ of tissue deformations compared to a situation when no NPWT dressing is applied [23]. Other authors suggested increased blood flow, decreased lateral and shear stress at the suture lines with decreased risk of wound dehiscence, and increased lymph clearance with reduced formation of hematoma/ seroma [24].

A recent meta-analysis was conducted by Strugala et al. [25] on the impact of prophylactic use of a specific design of NPWT device on surgical site complications. Articles were identified in which the specific single-use NPWT device (PICO ${ }^{\diamond}$, Smith \& Nephew) was compared with standard care for surgical site infection (SSI), dehiscence, or length of stay (LOS). Risk ratio (RR) $\pm 95 \%$ confidence interval (CI) (SSI; dehiscence) or mean difference in $\operatorname{LOS} \pm 95 \%$ CI was calculated using RevMan v5.3.

Combining all 16 studies, there was a significant reduction in SSI of $58 \%$ from $12.5 \%$ to $5.2 \%$ with NPWT (RR 0.43, [95\% CI 0.32-0.57], $p<0.0001$ ). Similar effects were seen irrespective of the kind of surgery (orthopedic, abdominal, colorectal, or cesarean section), although the numbers needed to treat (NNT) were lower in operations with higher frequencies of complications. There was a significant reduction in dehiscence from $17.4 \%$ to $12.8 \%$ with NPWT (RR 0.71 , [95\% CI $0.54-0.92], p<0.01)$. The mean reduction in hospital LOS by NPWT was also significant $(-0.47$ days, [95\% $\mathrm{CI}-0.71$ to -0.23$], p<0.0001)$. The significant reduction in SSI, wound dehiscence, and LOS on the basis of pooled data from 16 studies shows a benefit of the PICO single-use NPWT system compared with standard care in closed surgical incisions (• Table 57.1).

Another study focused on the interest of CiNPWT after post-SSI revision of orthopedic implants [26] for total hip arthroplasty (THA) due to septic loosening in the presence of active fistula. They were treated with a PICO ${ }^{\circledR}$ device for NPWT, in combination with the standard treatment for prosthesis infection. Resolution of the infectious process and healing of the surgical wound without complications were considered promising results, confirming the interest of the system in most of the surgical disciplines (plastic surgery, thoracic and cardiac surgeries, and colorectal surgery) $[27,28]$. The system has also demonstrated efficiency in stabilizing skin grafting.

\subsection{Conclusion}

The recent development of technologies proposing a mechanical restriction of micromovements on the suture line, with or without negative pressure, tends to demonstrate some evidenced benefits. These techniques are presently used in several surgical disciplines and proposed for at-risk situations in long and difficult procedures and also for minimizing the scar visibility and preventing enlargement as well as volume changes.

\section{- Take Home Message \\ This chapter expoes the interest of mechanotherapy during the post operative period in prevention of pathological scarring and in prevention of postop dehiscence and infection. Several techniques, from adhesive sutures to sophisticated machines applying on the suture edges a negative pressure, have already demosntrated an interest in decreasing the surgical site infection rates. These techniques are exposed and detailed. \\ Postop mechanotherapy seems adapted in patients at risk of developing local co:plications.}

\section{References}

1. Lancerotto L, Orgill DP. Mechanoregulation of angiogenesis in wound healing. Wound Repair Regen. 2014;22(5):557-68. https://doi.org/10.1111/wrr.12215.

2. Suarez E, Syed F, Rasgado TA, Walmsley A, Mandal P, Bayat A. Skin equivalent tensional force alters keloid fibroblast behavior and phenotype. Aesthet Plast Surg. 2014;38(4):767-78 https://doi.org/10.1007/s00266-014-0339-x. Epub 2014 Jun 10.

3. Ogawa R, Okai K, Tokumura F, Mori K, Ohmori Y, Huang C, et al. The relationship between skin stretching/contraction and pathologic scarring: the important role of mechanical forces in keloid generation. Wound Repair Regen. 2012;20(2):149-57. https://doi.org/10.1111/j.1524-475X.2012.00766.x. Epub 2012.

4. Roques C. Pressure therapy to treat burn scars. Wound Repair Regen. 2002;10(2):122-5.

5. Kilpadi DV, Lessing C, Derrick K. Healed porcine incisions previously treated with a surgical incision management system: mechanical, histomorphometric, and gene expression properties. Biophys J. 2014;106(4):932-43. https://doi.org/10.1016/j. bpj.2013.12.002.

6. Venclauskas L, Grubinskas I, Mocevicius P, Kiudelis M. Reinforced tension line versus simple suture: a biomechanical study on cadavers. Acta Chir Belg. 2011;111(5):288-92. 
7. Mustoe TA, Cooter RD, Gold MH, Hobbs FD, Ramelet AA, Shakespeare PG, Stella M, Téot L, Wood FM, Ziegler UE, International Advisory Panel on Scar Management. International clinical recommendations on scar management. Plast Reconstr Surg. 2002;110(2):560-71.

8. Ahn ST, Monafo WW, Mustoe TA. Topical silicone gel: a new treatment for hypertrophic scars. Surgery. 1989;106(4):781-6; discussion 786-7.

9. O'Brien L, Jones DJ. Silicone gel sheeting for preventing and treating hypertrophic and keloid scars. Cochrane Database Syst Rev. 2013;9:CD003826.

10. Reiffel RS. Prevention of hypertrophic scars by long-term paper tape application. Plast Reconstr Surg. 1995;96(7):1715-8.

11. Templeton MM, Krebs AI, Kraus KH, Hedlund CS. Ex vivo biomechanical comparison of V-LOC $180 \AA$ absorbable wound closure device and standard polyglyconate suture for diaphragmatic herniorrhaphy in a canine model. Vet Surg. 2015;44(1):659. https://doi.org/10.1111/j.1532-950X.2014.12201.x. Epub 2014 Jun 24.

12. Gurtner GC, Dauskardt RH, Wong VW, et al. Improving cutaneous scar formation by controlling the mechanical environment: large animal and phase I studies. Ann Surg. 2011;254:217-25.

13. Longaker MT, Rohrich RJ, Greenberg L, Furnas H, Wald R, Bansal V, et al. A randomized controlled trial of the embrace advanced scar therapy device to reduce incisional scar formation. Plast Reconstr Surg. 2014;134(3):536-46. https://doi. org/10.1097/PRS.0000000000000417.

14. Téot L, Boissière F, Bekara F, Herlin C, Fluieraru S. Contrôle de la tension des berges cicatricielles après résection cutanée : un nouveau dispositif médical adhésif réglable. [Control of the skin edge tension after resection: a new adjustable, adhesive medical device.]. Revue Francophone de Cicatrisation. 2017;1(1):46-50.

15. Carli AV, Spiro S, Barlow BT, Haas SB. Using a non-invasive secure skin closure following total knee arthroplasty leads to fewer wound complications and no patient home care visits compared to surgical staples. Knee. 2017;24(5):1221-5.

16. Ko JH, Yang IH, Ko MS, Kamolhuja E, Park KK. Do zip-type skin-closing devices show better wound status compared to conventional staple devices in total knee arthroplasty? Int Wound J. 2017;14(1):250-4. https://doi.org/10.1111/iwj.12596.

17. Tanaka Y, Miyamoto T, Naito Y, Yoshitake S, Sasahara A, Miyaji K. Randomized study of a new noninvasive skin closure device for use after congenital heart operations. Ann Thorac Surg. 2016;102(4):1368-74. https://doi.org/10.1016/j.athoracsur.2016.03.072. Epub 2016 Jun 1. PubMed PMID: 27261084.
18. Mitwalli H, Dolan C, Bacigalupi R, Khorasani H. A randomized, controlled, prospective clinical study comparing a novel skin closure device to conventional suturing. J Am Acad Dermatol. 2016;74(1):173-4. https://doi.org/10.1016/j.jaad.2015.08.004. PubMed PMID: 26702797.

19. Gorsulowsky D, Talmor G. A novel noninvasive wound closure device as the final layer in skin closure. Derm Surg. 2015;41(8): 987-9. https://doi.org/10.1097/DSS.0000000000000399.

20. Reddix RN Jr, Leng XI, Woodall J, Jackson B, Dedmond B, Webb LX. The effect of incisional negative pressure therapy on wound complications after acetabular fracture surgery. J Surg Orthop Adv. 2010;19:91-7.

21. Wilkes RP, Kilpaldi DV, Zhao Y, Kazala R, McNulty A. Closed incision management with negative pressure wound therapy (CIM): biomechanics. Surg Innov. 2012;19:67-75.

22. Kilpadi DV, Cunningham MR. Evaluation of closed incision management with negative pressure wound therapy (CIM): hematoma/seroma and involvement of the lymphatic system. Wound Repair Regen. 2011;19:588-96.

23. Torbrand C, Anesäter E, Borgquist O, Malmsjö M. Mechanical effects of negative pressure wound therapy on abdominal wounds - effects of different pressures and wound fillers. Int Wound J. 2018;15(1):24-8. https://doi.org/10.1111/iwj.12810. Epub 2017 Nov 23.

24. Hyldig N, Birke-Sorensen H, Kruse M, Vinter C, Joergensen JS, Sorensen JA, Mogensen O, Lamont RF, Bille C. Meta-analysis of negative-pressure wound therapy for closed surgical incisions. Br J Surg. 2016;103(5):477-86.

25. Strugala V, Martin R. Meta-analysis of comparative trials evaluating a prophylactic single-use negative pressure wound therapy system for the prevention of surgical site complications. Surg Infect. 2017;18(7):810-9. https://doi.org/10.1089/sur.2017.156. Epub 2017 Sep 8.

26. Miyahara HS, Serzedello FR, Ejnisman L, Lima Allm Vicente JRN, Helito CP. Incisional negative-pressure wound therapy in revision total hip arthroplasty due to infection. Acta Ortop Bras. 2018;26(5):300-4. https://doi.org/10.1590/1413785220182605196038.

27. Conde-Green A, Chung TL, Holton LH III, et al. Incisional Negative-Pressure Wound Therapy versus conventional dressings following abdominal wall reconstruction. A comparative study. Ann Plast Surg. 2013;71(4):394-7.

28. Stannard JP, Volgas DA, McGwin G, et al. Incisional negative pressure wound therapy after high-risk lower extremity fractures. J Orthop Trauma. 2012;26(1):37-42.

Open Access This chapter is licensed under the terms of the Creative Commons Attribution 4.0 International License (http://creativecommons. $\mathrm{org} /$ licenses/by/4.0/), which permits use, sharing, adaptation, distribution and reproduction in any medium or format, as long as you give appropriate credit to the original author(s) and the source, provide a link to the Creative Commons license and indicate if changes were made.

The images or other third party material in this chapter are included in the chapter's Creative Commons license, unless indicated otherwise in a credit line to the material. If material is not included in the chapter's Creative Commons license and your intended use is not permitted by statutory regulation or exceeds the permitted use, you will need to obtain permission directly from the copyright holder.

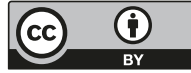

